\title{
Development of Modern Steels for Strain Based Design Pipe Lines and Simulation Results
}

\author{
Christoph Heering ${ }^{1, a,{ }^{*}, \text { Kirill Tokmakov }}{ }^{1, b}$ and Ingo Schuster ${ }^{1, c}$ \\ ${ }^{1} \mathrm{SMS}$ group $\mathrm{GmbH}$, Research \& Development, Materials Technology, Düsseldorf, Germany \\ ${ }^{a}$ Christoph.Heering@sms-group.com, ${ }^{b}$ Kirill.Tokmakov@sms-group.com \\ IIngo.Schuster@sms-group.com
}

\begin{abstract}
Keywords: Heavy plate, strain based design, microstructure development, mechanical properties, precipitation control, recrystallization, retained austenite.
\end{abstract}

\begin{abstract}
Due to the exploration of gas and oil sources in remote regions with harsh environment, the pipe line designers are faced with the challenging conditions. Especially in the cases where displacement-controlled loads are the predominant design condition, such as ground movement, strain-based design is applied instead of stress-based design to build safer pipelines and to assure the integrity of the lines along their lifetimes. It requires steels to have a large strain hardening capacity, long uniform elongation, and good toughness to achieve a well-defined and sufficient plastic deformation. In order to fulfil the requirements, all the processing steps are supposed to be well designed, for example, the chemical composition, microstructural design, thermo-mechanical controlled process (TMCP) and heat treatment, etc. In general pipe line steel has a low carbon, high manganese content combined with a certain amount of micro-alloying elements as $\mathrm{Nb}$, $\mathrm{Ti}$ and sometimes B. Using Thermo-mechanical rolling and cooling schedules excellent combinations of strength and toughness can be established. To successfully produce steel plates for strain based design pipe lines the actual heating rolling and cooling technologies must be developed further as well as the equipment to produce such steel. The paper gives an overview about modern plate mill equipment and new setup strategies for the production of heavy plates X70 to X100 as well as the thermo-dynamic simulations used during the development.
\end{abstract}

\section{Introduction}

Conventionally pipelines are designed by limiting the hoop stress in the pipe wall by a design factor on the specified minimum yield stress. It refers to the stress based design, which has been adopted as the major guideline in the design of line pipes for many years. However the stress based design tends to be relatively conservative for those under displacement-control or partly displacement-control, such as pipelines in seismic regions, landslide areas and subsea environment. Compared with stress based design, strain based design is proposed as a more economic and reasonable choice under the conditions where displacement-controlled loads are predominant. In such approach, strain capacity is estimated directly instead of being derived from an allowable stress. As a consequence, the safety margin upon strain capacity will correspond with the conservativeness, and there is no extremely sensitive conversion from stress to strain [1]. The pipes based on strain based design shall be able to suffer longitudinal strains in such a way that the pipe dislocates the amount of strain by work hardening over a long distance. The requirements to the pipe material are specified uniform elongation and in some cases special shapes for the stress strain curve from longitudinal tensile tests [2].

\section{Microstructure of Modern Pipeline Steels}

Due to the key variable of the final microstructure in determining material properties, it must be specifically designed to ensure safe and optimal performance under operating conditions. In industrial "conventional" plates there is a general tendency of reducing carbon content to obtain 
lower Bainite microstructure [3]. However, the majority of modern pipeline steels have different and complex microstructural arrangements depending on their chemical compositions and processing routes (e.g. TMCP $+\mathrm{ACC}$ ). The new steel grads developed for strain-based design applications can have various microstructures consisting of different forms and combinations of Bainite, Martensite and Ferrite (see Fig 1a-c) in order to achieve the target strength, toughness and ductility [4].

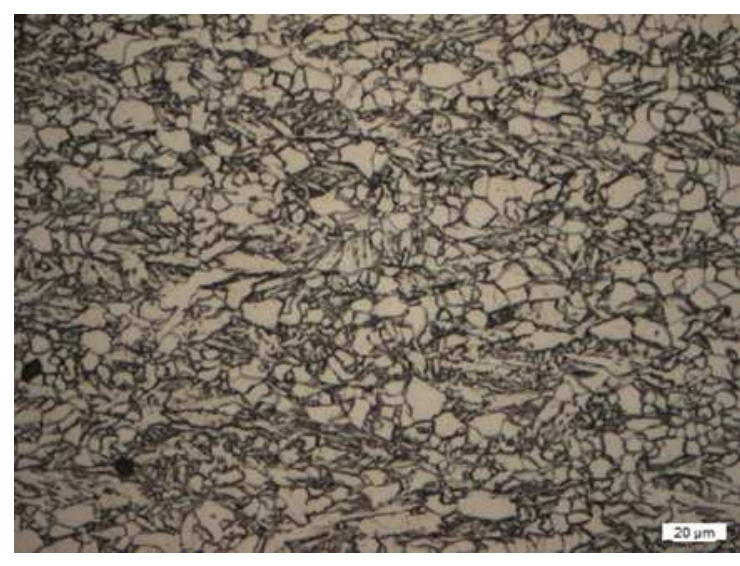

Fig. 1a. Microstructure of pipeline steel grade X70 (polygonal Ferrite and Bainite)

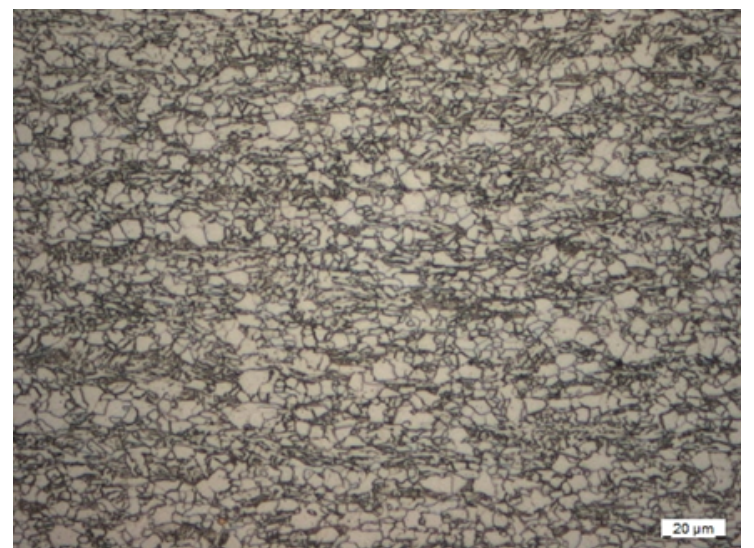

Fig. 1b. Microstructure of pipeline steel grade X80 (mainly bainitic microstructure)

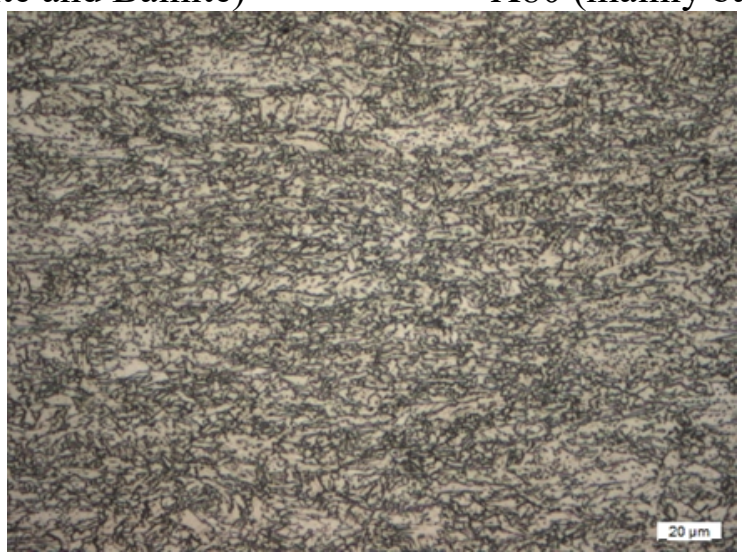

Fig. 1c. Microstructure of pipeline steel grade X100 (acicular Ferrite and Bainite)

\section{Experimental Procedure}

The chemical compositions of the micro-alloyed steels for strain based designed pipeline steels vary for different product thickness to meet mechanical property requirements (e.g X70, X80, $\mathrm{X} 100)$. Modern alloying concepts have a manganese (Mn) content up to $2.0 \mathrm{wt} \%$ and very low carbon content $(<0.1 \mathrm{wt} \% \mathrm{C})$ and also minor additions of micro-alloying elements $(\mathrm{Nb}, \mathrm{V}, \mathrm{Ti})$. Molybdenum (Mo) promotes the formation of the lower Bainite microstructure. (see Tab.1).

Table 1. Chemical composition of the investigated material in wt.-\%

\begin{tabular}{|c|c|c|c|c|c|c|c|c|c|}
\hline & $\mathrm{C}$ & $\mathrm{Si}$ & $\mathrm{Mn}$ & $\mathrm{Cr}$ & $\mathrm{Mo}$ & $\mathrm{Ni}$ & $\mathrm{Ti}$ & $\mathrm{Nb}$ & $\mathrm{Cu}$ \\
\hline wt. $\%$ & $<0.1$ & $<0.3$ & $<2.0$ & $<0.1$ & $<0.5$ & $<0.1$ & $<0.1$ & $<0.1$ & $<0.1$ \\
\hline
\end{tabular}

Steels grades for strain based design applications have various microstructures consisting of Ferrite, Bainite and finely dispersed Martensite-Austenite constituent (M/A phase). The main challenge lies on the steel composition and the adjusted thermo-mechanical treatment in the plate production process. In order to produce complex microstructures the most important parameters for influencing the microstructure formation are the cooling start temperature, cooling rate and cooling 
stop temperature. For this reason dilatometer test were conducted with varying simulation of the plate cooling process and the microstructure was investigated concerning the amount of retained austenite.

Dilatometer Tests. The simulation of plate production was performed using a deformation dilatometer (DIL 805A/D, Fig.2). The dilatometer allows a controlled thermomechanical treatment including heat treatment under vacuum atmosphere and a multi-step simulation of the plate rolling. The double compression test was applied for simulation of roughing- and finishing phase of plate production.
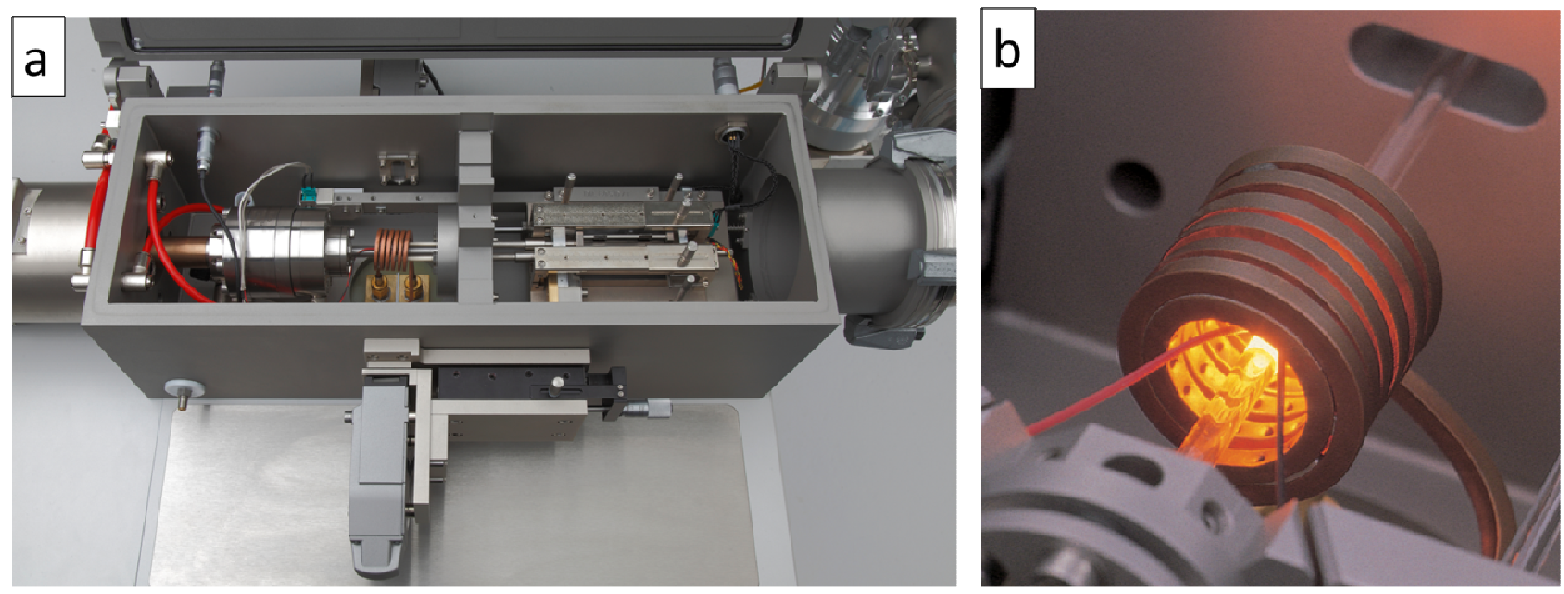

Fig. 2. (a) A deformation mold of DIL805A/D Dilatometer for compression tests; (b) A sample was inductively heated in a quenching mold [i]

The test involves reheating to ensure precipitates dissolve back into solution, controlled cooling to deformation temperature (roughing phase, finishing phase), cooling to start temperature of ACC, various cooling start and stop temperature of ACC and slow cooling after ACC.

M/A Phase Depending on Cooling Start Temperature and Cooling Stop Temperature. The cooling process determines the final microstructure and properties of the rolled plate. Regarding the formation of M/A-phase several tests with varying start- and stop temperature of ACC were conducted.

\section{a) Cooling start temperature}

After the last rolling pass of the finishing phase at $\mathrm{T}=800^{\circ} \mathrm{C}$, the samples were cooled with the same cooling rate of $t=1 \mathrm{~K} / \mathrm{s}$ to different start cooling temperatures from $780{ }^{\circ} \mathrm{C}$ to $640{ }^{\circ} \mathrm{C}$. Then the samples were cooled down fast to $\mathrm{T}=250{ }^{\circ} \mathrm{C}$ with the cooling rate of $t=30 \mathrm{~K} / \mathrm{s}$ followed by slow cooling to room temperature with the cooling rate of $t=2 \mathrm{~K} / \mathrm{s}$. The time-temperature profile for delay cooling is schematically shown in Fig. 3.

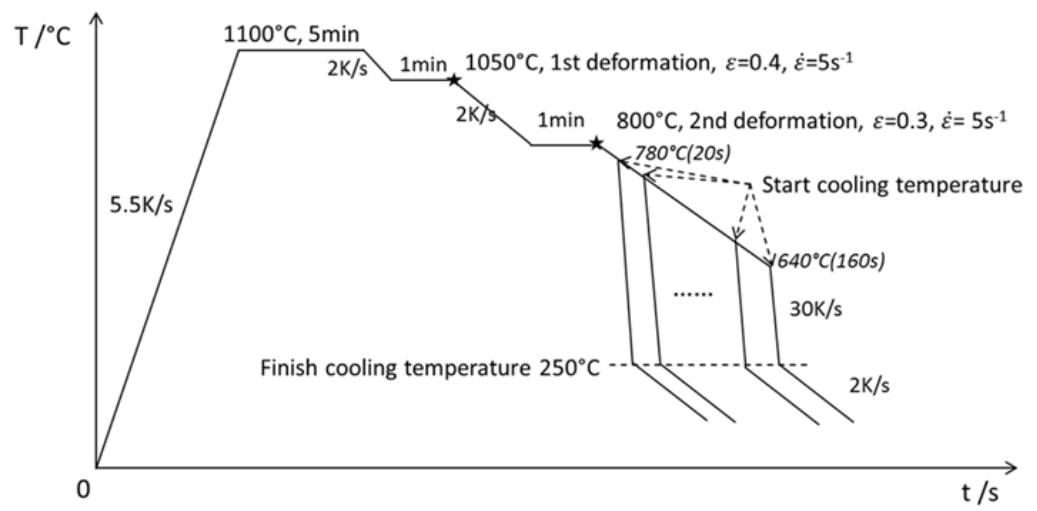

Fig. 3. Time-Temperature profile of dilatometer test with varying cooling start temperature 
b) Cooling stop temperature

In the tests for different finish cooling stop temperatures, the deformation steps were the same as those for tests of cooling start temperature. After the finishing phase at $\mathrm{T}=800{ }^{\circ} \mathrm{C}$, the samples were cooled to $\mathrm{T}=760^{\circ} \mathrm{C}$ with a cooling rate of $T=1 \mathrm{~K} / \mathrm{s}$. They were then fast cooled down to the target finish cooling temperature with the cooling rate of $t=30 \mathrm{~K} / \mathrm{s}$ again followed by slow cooling with a cooling rate of $t=2 \mathrm{~K} / \mathrm{s}$ (Fig.4).

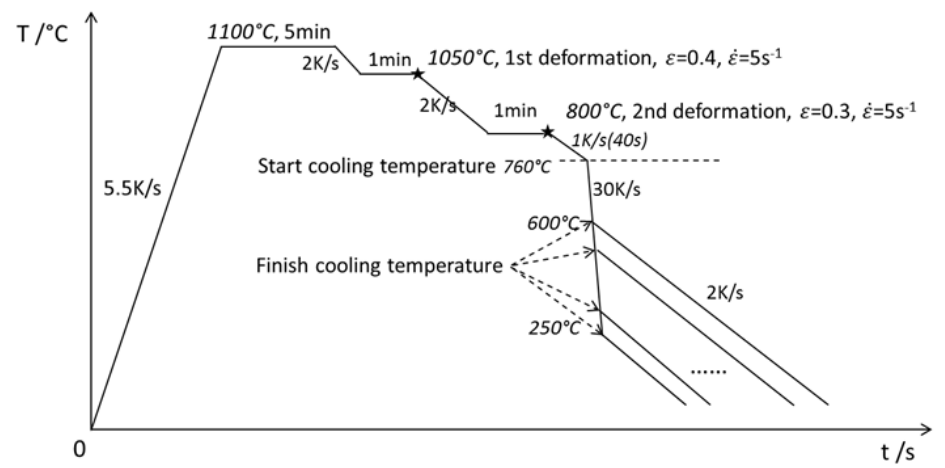

Fig. 4. Time-Temperature profile of dilatometer test with varying cooling stop temperature

Microstructure Observation. All samples were investigated regarding volume fraction of retained austenite and distribution of M/A-constituents in the matrix. The volume fraction of retained austenite was measured by X-ray diffraction method and the distribution of austenite in the material was investigated by using etching method (LePera) and microstructure evaluation under light optical microscope. The optical microscopy is the simplest method for studying the formation of M/A-phase in the microstructure. It gives information over the microstructure and its morphology (e.g. distribution of M/A-phase in the microstructure).

\section{Results and Discussion}

The Figure 5 shows the volume fraction of retained austenite depending on cooling start and cooling stop temperature. The content of retained austenite of the investigated material is strongly depending on cooling parameters.
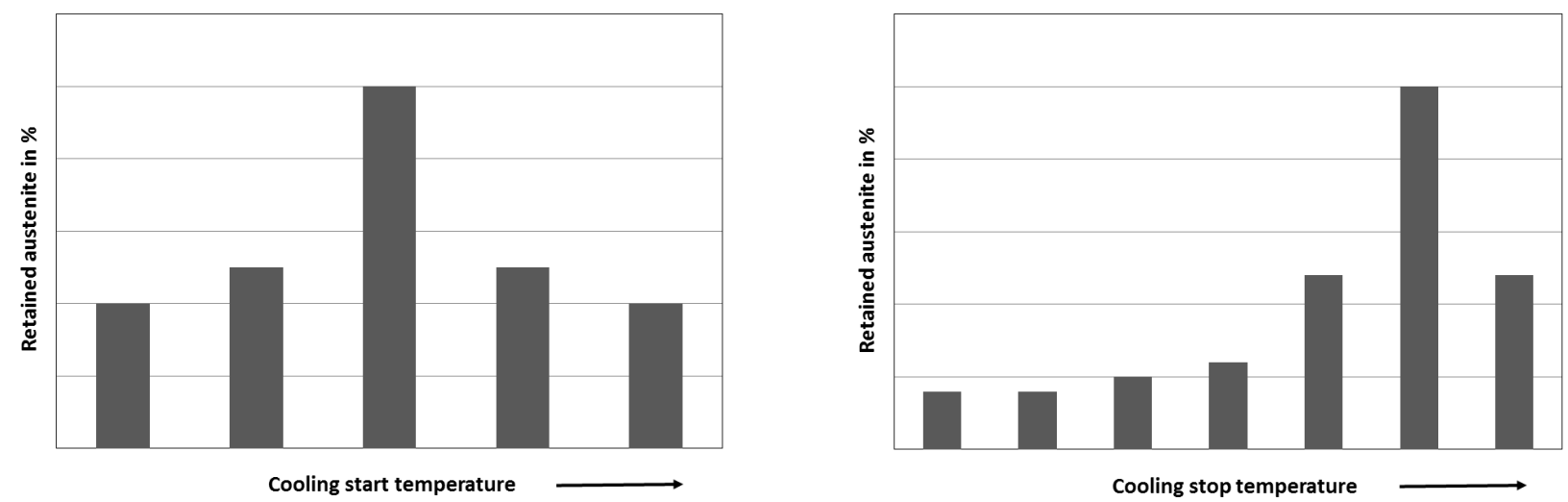

Fig. 5. Results of X-Ray measurement for dilatometer samples:

Simulation of cooling start (left) and cooling stop temperature (right) of ACC in plate production 

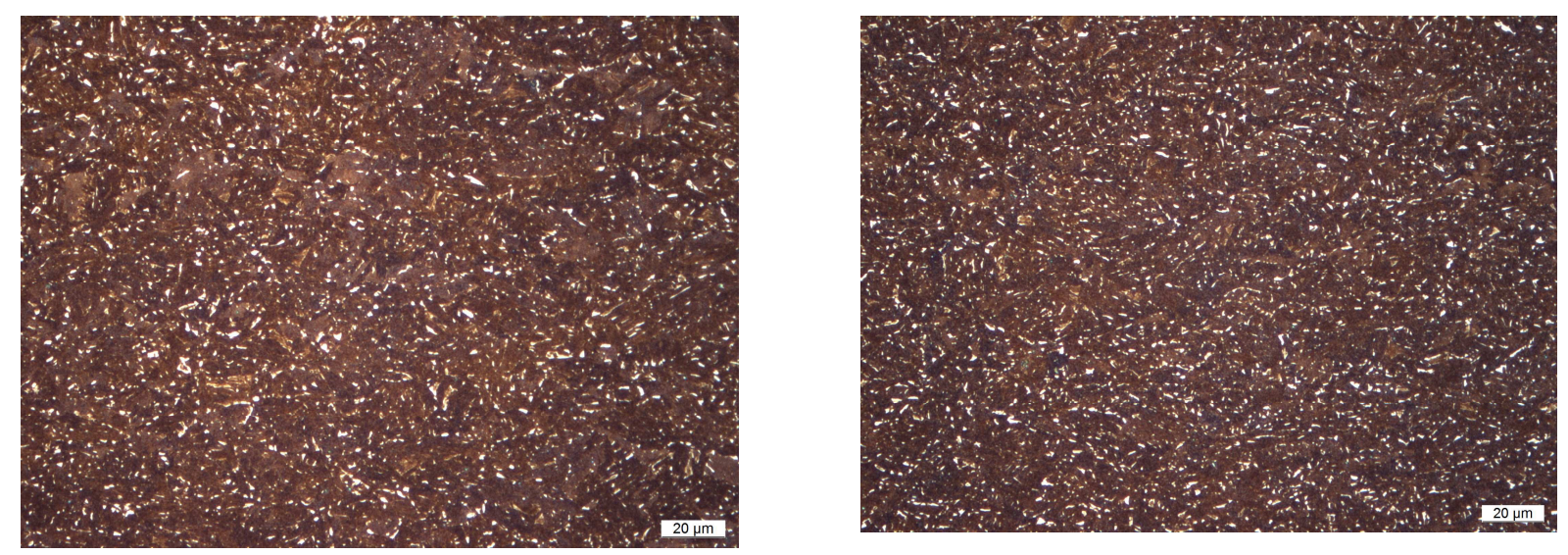

Fig. 6. Results of optical microscopy for dilatometer samples:

Distribution of M/A-phase particles for different cooling strategies in plate production $(\mathrm{M} / \mathrm{A}-\mathrm{phase}=$ white dotted structure $)$

The M/A-phase distribution is shown in Figure 6. The white islands-like components in each figure are retained austenite or M/A-constituents which are fine-dispersed in the matrix. Thus the controlled and on the material composition adapted ACC is required to achieve a certain volume fraction of retained austenite. The distribution of M/A-phase particles in the matrix is mainly independent of accelerated cooling parameters.

The results of laboratory tests were applied to real plate production.

\section{Simulation Aided Production}

The thermo-mechanical treatment in plate production process is one of challenges in the production of steels for strain based design applications. Advanced physical models describing the microstructure development during thermo-mechanical production are needed for better and precise setup of plate mill and to achieve the desired final microstructure and properties.

The new metallurgical processes model covers and combines all process steps, such as, a model for solution and dissolution of precipitations of micro-alloying elements starting with slab preheating, a model for the austenite grain growth during reheating as well as a recrystallization and grain growth model for hot rolling. Finally a model for the austenite decomposition has to describe the transformation dynamics after deformation.

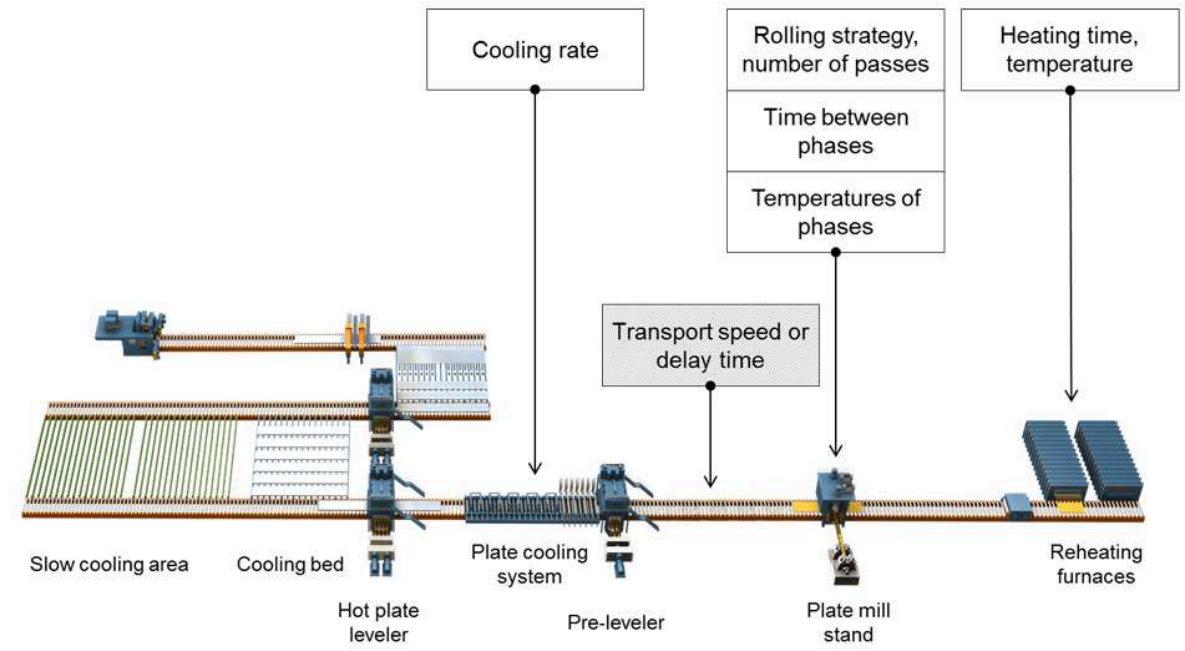

Fig. 7. Interaction of model with rolling process especially for strain based design steels 
The microstructure model covers the entire production process from slab reheating up to the cooling of the rolled sheet in a high performance cooling device (see Figure 7). By applying the precipitation and grain growth model into the reheating control, the heating temperature and the heating time are adjusted to fully utilize the potential of the micro-alloying elements.

A special microstructure model, based on the simulation of strain induced precipitation and calculation of the residual strain is used to determine the deformation strength of the rolled steel. This has a significant influence on the accuracy of the force precalculation and thus on the geometrical tolerances and to the flatness of the finished product. Furthermore, the microstructure model as part of pass schedule calculator provides the austenite grain size and residual strain to the austenite transformation model [5]. The sub-models and their parameters are being verified and tuned using laboratory tests and real plate rolling results.

In the case of the steel for strain based design application the transport time between the rolling stand and cooling line must be adjusted more precisely due to necessary Austenite/Ferrite transformation and carbon enrichment of austenite before fast cooling which is a condition for M/A constituent. It is done by utilization of austenite decomposition model not only as part of process model of cooling line but already on the transport roller table by the time delay needed for phase transformation. Simultaneously the model must monitor other diffusion controlled transformations and avoid the cementite precipitation in the delay time. It means that the microstructure model becomes a trigger for the start of the fast cooling in case a sufficiently amount of ferrite is transformed from the deformed austenite. From the software architecture point of view the austenite transformation model becomes a part of the pass schedule calculator and decides if the rolled plate can be handed over to the cooling device. The output of microstructure model for residual strain (a) and start of ferrite transformation (b) is shown in Figure 8. The dashed line is the time point where the rolled plate reaches the ACC and is being cooled down at a fast cooling rate to the finish cooling temperature to promote the bainitic transformation and finally the incomplete martensitic transformation.

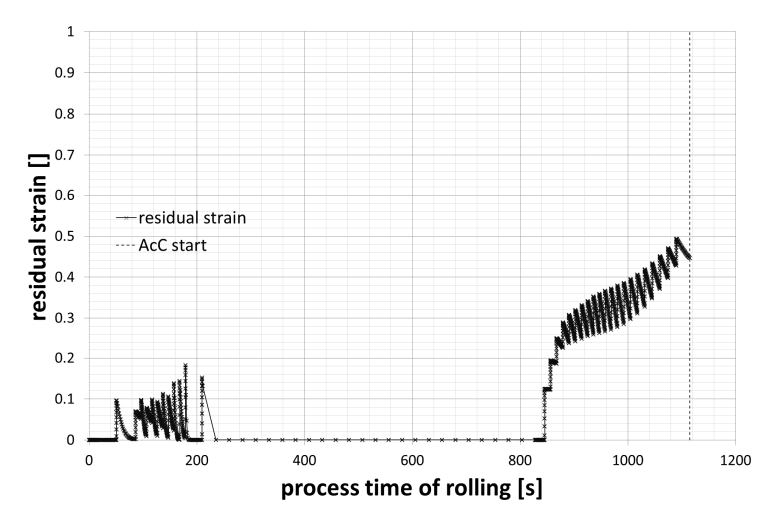

(a)

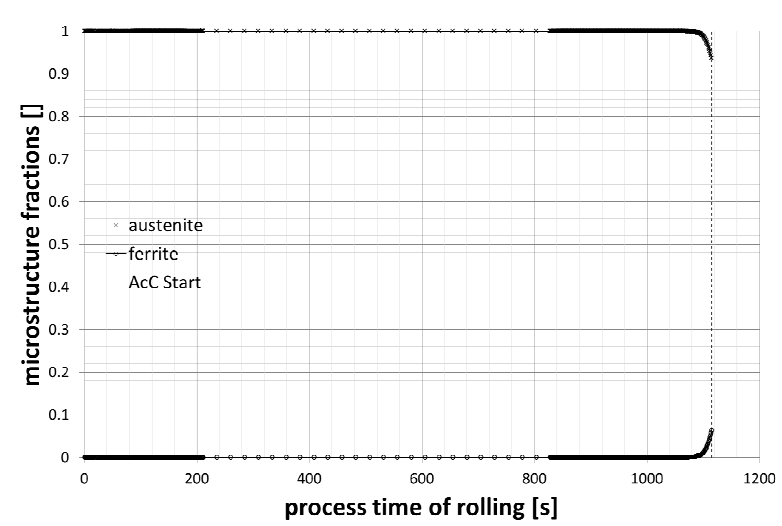

(b)

Fig. 8. Plate rolling process model output

The applied austenite decomposition model is based on the JMAK theory where the kinetic constants are described by a regression model for the austenite-ferrite and austenite-pearlite transformation. The data for the regression model were being obtained from a physical model for diffusion controlled transformation DICTRA [6]. This model focuses only on ferrite and pearlite transformation which are possible on the transport roller table.

\section{Summary}

Plates for line pipes complying with the strain based design philosophy have to combine the target strength, toughness and ductility with a sufficient amount of uniform elongation. This combination of properties needs a final microstructure that contains a certain and fine dispersed amount of 
Martensite/Austenite islands. Laboratory tests were carried out to determine the technological window for a given steel chemistry. To stay within this technological window, an advanced material model was developed to assist the mill setup system. It considers all thermodynamic processes during plate processing as Nitride dissolution during slab reheating, strain induced precipitation and recrystallisation processes during thermomechanical rolling as well as a phase transformation of the deformed Austenite prior to the final cooling of the plates.

\section{References}

[1] H. Stijn, Coupled Experimental-Numerical Framework for the Assessment of Strain Capacity of Flawed Girth Welds in Pipelines. 2012

[2] C. Kalwa, H.G. Hillenbrand, View of a Pipe Manufacturer to the Developments for Linepipe Material. EUROPIPE GmbH, Pipeline Technology Journal 2013

[3] L. Zheng, S. Gao, Production and Application of High Strength and High Toughness Pipeline Steel with Acicular Ferrite, BAO Steel Corporate Publications, 2005

[4] D. Belato Rosado, W.De Waele, D. Vanderschueren, S. Hertele, Latest developments in mechanical properties and metallurgical features of high strength line pipe steels. Sustainable Construciton and Design. 2013

[5] K. Tokmakov, J. Lemke, U. Grafe, C. Heering, Microstructure simulation with focus on hot rolling of high strength heavy plates, SMS Siemag AG. MEFORM 2013; 2013

[6] http://www.thermocalc.com/ 